This item was submitted to Loughborough's Research Repository by the author.

Items in Figshare are protected by copyright, with all rights reserved, unless otherwise indicated.

\title{
Product differentiation in a vertical structure
}

PLEASE CITE THE PUBLISHED VERSION

https://doi.org/10.1515/bejte-2020-0037

PUBLISHER

Walter de Gruyter GmbH

VERSION

VoR (Version of Record)

PUBLISHER STATEMENT

This paper was published in the journal The B.E. Journal of Theoretical Economics and is available at https://doi.org/10.1515/bejte-2020-0037.

\section{LICENCE}

All Rights Reserved

\section{REPOSITORY RECORD}

Han, Tien-Der, M Emranul Haque, and Arijit Mukherjee. 2020. "Product Differentiation in a Vertical Structure". Loughborough University. https://hdl.handle.net/2134/13619177.v1. 


\section{Research Article}

\section{Tien-Der Han, M. Emranul Haque and Arijit Mukherjee* Product Differentiation in a Vertical Structure}

https://doi.org/10.1515/bejte-2020-0037

Received March 14, 2020; accepted September 27, 2020

Abstract: We consider final goods producers' preference for horizontal product differentiation in the presence of strategic input price determination. Final goods producers may not prefer maximal differentiation but may prefer moderate differentiation under both Cournot and Bertrand competition in the final goods market if product differentiation does not increase the market size significantly and there is either free entry in the input market or the input supplier has increasing returns to scale technology. Thus, we provide a new rationale for moderate product differentiation. Our reasons are different from the existing reasons of mixed pricing strategy, endogenous leadership, no-buy option for the consumers and the relative performance incentive schemes.

Keywords: entry, final goods, increasing returns, input, product differentiation JEL Classification: D43, L11, L13

\section{Introduction}

There is a debate regarding firms' preference for horizontal product differentiation, which helps to increase profits by reducing competition. It follows from Singh and Vives (1984) that firms prefer maximal product differentiation. Fanti and Meccheri (2014) and Inomata (2018) also show that firms prefer maximal

\footnotetext{
*Corresponding author: Arijit Mukherjee, Nottingham University Business School, Jubilee Campus, Wollaton Road, Nottingham, NG8 1BB, UK; CESifo, Munich, Germany; INFER, Cologne, Germany; and GRU, City University of Hong Kong, Kowloon Tong, Hong Kong, E-mail: arijit.mukherjee@nottingham.ac.uk. https://orcid.org/0000-0002-9611-2888 Tien-Der Han, Loughborough University, Loughborough, UK

M. Emranul Haque, Department of Economics, The University of Manchester, Manchester, UK
} 
differentiation. ${ }^{1}$ In contrast, Haskel, Iozzi, and Valletti (2013) and Kawasaki and Matsushima (2019) show that firms may prefer minimal differentiation. Haskel, Iozzi, and Valletti (2013) consider two types of product substitutability in the airline industry - between the pair of routes from the same airport and between the airports. They find that the airlines prefer minimal difference for the former but maximal difference for the latter. Considering the airline industry, Kawasaki and Matsushima (2019) find that profit can be maximised at minimal differentiation.

While these papers provide important insights, they did not pay much attention to a common phenomenon, viz., vertical relationship, which can be observed in many industries, such as automobile, computer, cellular phones and construction. The purpose of this paper is to fill this gap by analysing firms' preference for horizontal product differentiation under vertical relationship.

Our motivation for looking at the implications of vertical relationship also comes from the recent literature showing that the presence of vertical relationship may alter the relationship between competition and profit significantly. Considering homogeneous products and free entry in the input sector, Matsushima (2006) shows that more final goods producers increase total profits of the final goods producers by reducing the input price. Wang and Lee (2015) show that more final goods producers increase total profits of the final goods producers in the presence of free entry in the input sector if knowledge spillover from R\&D in the final goods market is high and the entry cost in the input sector is moderate. Mukherjee (2019) shows that if the final goods are sufficiently differentiated, more firms in the final goods market create a favourable input-price effect and increase the profits of each final goods producer in the presence of free entry in the input sector. ${ }^{2}$

The striking implications of the input market discussed above motivate us to analyse the effects of the input market on firms' preference for horizontal product differentiation that has been overlooked in the literature. In this respect, we show

\footnotetext{
1 Fanti and Meccheri (2014) and Inomata (2018) show U-shaped relationships between product differentiation and firm's profits, where profits are maximised at maximal differentiation.

2 While these papers look at symmetric firms, as considered in the present paper, Mukherjee, Broll, and Mukherjee $(2008,2009)$ show that more firms in the final goods market can increase respectively the total profits of the final goods producers and the profit of each final goods producer in the presence of cost asymmetry among the final goods producers. In an earlier paper, Tyagi (1999) shows that more final goods producers may increase the profit of each final goods producer in the presence of a monopoly input supplier if the demand function for the final goods is sufficiently convex. Unlike the papers mentioned in the text considering successive oligopoly models, Naylor (2002) show that more final goods producers can increase total profits of the final goods producers in the presence of firm-specific bargaining between the final goods producers and the input suppliers.
} 
how market expansion following horizontal product differentiation affects the decision for product differentiation. Since horizontal product differentiation is often used to measure competition (Aghion et al. 2005; Raith 2003; Sacco and Schmutzler 2011), our results also show whether firms prefer to create less competition through horizontal product differentiation under a vertical relationship.

We show in Section 2 that if product differentiation does not increase the market size significantly, the final goods producers may not prefer maximal product differentiation (i.e., may not prefer minimum competition) but may prefer moderate differentiation under free entry in the input market. This result occurs under both Cournot and Bertrand competition in the final goods market. This happens because product differentiation creates two opposing effects. Product differentiation reduces aggressive behaviour among the final goods producers, which reduces their outputs and the input demand. Lower input demand leads to fewer input suppliers or higher market concentration in the input market, which increases the input price. Hence, on one hand, increased differentiation tends to increase the profits of the final goods producers for a given input price by reducing competition, but on the other hand, it tends to reduce the profits of the final goods producers by increasing the input price. The rising input price may prevent the final goods producers from creating maximal differentiation.

The input-price effect mentioned above is responsible for our result of no maximal differentiation. This mechanism gets empirical support from Friedson and $\mathrm{Li}$ (2015), which show that more hospitals (the downstream agents) in an area attract more local independent medical labs (the upstream agents) providing intermediate services, like testing physical samples, to the hospitals (i.e., increased "input sharing”) and reduces prices of the intermediate services. Holmes (1999), Fee and Thomas (2004) and Li (2013) also provide the evidences of increased input sharing.

The mechanism discussed in Section 2 is more general than what is shown there. Our qualitative results hold even if there is no free entry in the input sector, but the above-mentioned input-price effect occurs depending on the market expansion effects of product differentiation. We show this in Section 3, where we consider a monopolist input supplier, thus considering an exogenously given input sector with no competition among the input suppliers, but assume that the input supplier has increasing returns to scale technology, which is consistent with the well-known fact that input productions often experience economies of scale (Besanko et al. 2013).

Considering a monopolist input supplier with increasing returns to scale technology, we show under both Cournot and Bertrand competition in the final goods market that the final goods producers may not prefer maximal product 
differentiation but may prefer moderate differentiation if product differentiation does not increase the market size significantly. This happens because of the inputprice effects discussed above. However, here the input-price effect is not created by market concentration in the input market, but it is created by the increasing returns in input production.

Our paper can be related to the literature following the seminal paper by Hotelling (1929), which shows that firms prefer minimal differentiation. Vickrey (1964) and D'Aspremont et al. (1979) corrected an error in Hotelling (1929) and showed that firms prefer maximal differentiation. Economides $(1984,1986)$ also support the conclusion of maximal differentiation. However, there is another set of papers which restore Hotelling's conclusion of minimal differentiation in the presence of collusion in prices (Friedman and Thisse 1993; Jehiel 1992) ${ }^{3}$, consumption externality (Cintio 2006), and consumers' incremental utility from purchasing multiple products and preference uncertainty (Guo 2006; Kim and Serfes 2006). ${ }^{4}$ There are some papers showing firms' preference for a moderate differentiation due to the presence of mixed pricing strategy (Osborne and Pitchik 1987), endogenous leader-follower structure (Meza and Tombak 2009), ${ }^{5}$ incentive delegation (Kou and Zhou 2015), and when not-buying a product is an option to the consumers (Pazgal, Soberman, and Thomadsen 2016).

There are few papers examining firms' preference for product differentiation in a Hotelling model with strategic input price determination. Matsushima (2004, 2009) show that when the transport costs faced by the upstream firms are small or the difficulty in converting inputs to the final goods is low (which are comparable to our case with no transportation cost faced by the upstream firms or no difficulty in converting inputs to the final goods), the firms prefer maximal differentiation. Considering bilateral bargaining between the input supplier and the final goods

3 Matsumura and Matsushima (2011) show that minimal differentiation does not occur in a collusive equilibrium if the firms differ in costs.

4 Although majority of papers using the Hotelling framework consider that firms locate within the "Hotelling line", there are papers which don't restrict firms to locate within the Hotelling line. It is shown that firms prefer larger differentiation when they are not restricted within the Hotelling line (see, e.g., Matsumura and Matsushima 2012; Tabuchi and Thisse 1995). There is another literature examining the conditions for maximal and minimal differentiation in a circular city model (see, e.g., Eaton and Lipsey 1975; Karlson 1985; Salop 1979). There is a strand of literature considering firms' location choice in linear cities or in circular cities with linear demand functions with substitutable or complementary goods. The results show that firms prefer maximal or minimal distance depending on the type of competition (Cournot or Bertrand), how the consumers are located (on a linear-city or on a circular-city) and whether the goods are substitutes or complements (Liang, Hwang, and Mai 2006; Pal 1998; Shimizu 2002; Sun 2014).

5 Matsumura and Matsushima (2010) extend Meza and Tombak (2009) to show the effects on R\&D investments, consumer surplus and welfare. 
producers, Brekke and Straume $(2004)^{6}$ show that the final goods producers prefer to increase differentiation as far as possible.

The papers mentioned in the previous paragraph differ from our paper in terms of the structure as well as the result. Unlike those papers considering inelastic unit demand function and price competition in the final goods market, we consider a successive oligopoly model under output and price competition in the final goods market with quadratic utility functions of the consumers which are affected by product differentiation. In contrast to these papers, we show that firms may not prefer maximal product differentiation depending on the input market structure, input production technology and the market expansion effect.

The remainder of the paper is organised as follows. Section 2 describes the model and shows the results under free entry in the input market. Section 3 considers increasing returns to scale technology in the input market. Section 4 concludes.

\section{Free Entry in the Input Market}

\subsection{Cournot Competition in the Final Goods Market}

Consider a successive oligopoly model like Matsushima (2006) and Mukherjee (2019) ${ }^{7}$ where $n(\geq) 2$ final goods producers produce horizontally differentiated products by using a critical input produced in an endogenously determined oligopolistic input market. Assume that each final goods producer requires one unit of input to produce one unit of the final goods.

While the number of final goods producers is given exogenously, there are many input suppliers and free entry in the input sector determines the number of active input suppliers. If an input supplier enters the market, it incurs a fixed entry cost, $K$. For simplicity, we normalise the marginal cost of input production to 0 . There are no other costs for input production. We also assume for simplicity that the only cost faced by the final goods producers is the price of the input.

Assume that the $i$ th final goods producer faces the inverse market demand function $P_{i}=1-\alpha q_{i}-g \sum_{\substack{j=1 \\ i \neq j}}^{n} q_{j}$, where $\alpha=1+s(n-1)(1-g)$, and $P_{i}$ and $q_{i}$ are the price and output of the ith good irrespectively. ${ }^{8}$ The term $g \in[0,1]$ shows the

6 Brekke and Straume (2004) don't restrict the final goods producers within the Hotelling line.

7 Mukherjee (2019) extends Matsushima (2006) with differentiated final goods.

8 This demand function is generated from the utility function $U=\sum_{i=1}^{n} q_{i}-\frac{1}{2}[1+s(n-1)(1-g)] \sum_{i=1}^{n} q_{i}^{2}-g \sum_{\substack{i, j=1 \\ i \neq j}}^{n} q_{i} q_{j}+\xi$, where $\xi$ is the numeraire good. 
degree of product differentiation and the term $s$ captures market expansion, which we explain below. The products are perfect substitutes (isolated) if $g=1(g=0)$.

Adding the inverse demand functions, we get $Q=\sum_{i=1}^{n} q_{i}=[1+(n-1) g+$ $s(n-1)(1-g)]^{-1} n[1-\bar{P}]$, where $\bar{P}=\frac{1}{n} \sum_{i=1}^{n} P_{i}$ denotes the average price. If $s=1$, the total output is independent of $g$. Hence, the demand function is like Shubik and Levitan (1980) for $s=1$, where product differentiation does not affect the market size. ${ }^{9}$ The total demand increases for $s<1$, and in the case of $s=0$, we get a demand function like Bowley (1924), where differentiation increases the market size completely. As $s$ reduces from 1 to 0 , the term $\alpha=1+s(n-1)(1-g)$ reduces from $\alpha=1+(n-1)(1-g)$ to $\alpha=1$. Thus, $s$ and $\alpha$ help to capture a wide range of demand functions from Shubik and Levitan (1980) to Bowley (1924), depending on the extent of market expansion. ${ }^{10}$

Consider a three-stage game. At stage 1, the input suppliers take the entry decision. At stage 2, the input suppliers who entered the market determine their outputs like Cournot oligopolists, and the input price, $w$, is determined. At stage 3, the final goods producers determine their outputs like Cournot oligopolists and the profits are realised. We solve the game through backward induction.

Given the input price $w$, the ith final goods producer determines its output by maximising the following expression:

$$
\operatorname{Max}_{q_{i}}\left(1-\alpha q_{i}-g \sum_{\substack{j=1 \\ i \neq j}}^{n} q_{j}-w\right) q_{i} .
$$

The equilibrium output is

$$
q_{i}^{c *}=\frac{1-w}{2-g+g n+2 s(1-g)(n-1)} .
$$

The total input demand is $n q_{i}^{c *}=I=\frac{n(1-w)}{2-g+g n+2 s(1-g)(n-1)}$, which gives $w^{c}=\frac{n-(2-g) I-g n I-2 s I(1-g)(n-1)}{n}$.

If $m$ input suppliers entered the market, the $k$ th input supplier determines its output by maximising the following expression:

9 Ardelean (2006) shows that consumer's love of variety can be very limited. It is shown in behavioural economics and behavioural finance that variety brought by product differentiation is not always "the more the merrier". The effect of "choice overload" may also suggest against love for variety (Iyengar and Kamenica 2010; Hefti 2018; Malone and Lusk 2017).

10 One may look at Choné and Linnemer (2020), which review the development of the linear demand systems following the introduction of a quasilinear quadratic utility model as the foundation of a linear demand system by Levitan and Shubik in the 1960s. 


$$
\operatorname{Max}_{I_{k}}\left(\frac{n-(2-g)\left(I_{k}+\sum_{\substack{z=1 \\ k \neq z}}^{m} I_{z}\right)-g n\left(I_{k}+\sum_{\substack{z=1 \\ k \neq z}}^{m} I_{z}\right)-2 s\left(I_{k}+\sum_{\substack{z=1 \\ k \neq z}}^{m} I_{z}\right)(1-g)(n-1)}{n}\right) I_{k},
$$

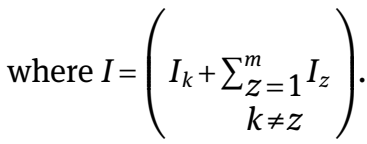

The equilibrium input production is

$$
I_{k}^{c *}=\frac{n}{(1+m)(2-g+g n+2 s(1-g)(n-1))} .
$$

Hence, for a given number of input suppliers, $m$, the equilibrium input price is $w^{c *}(m)=\frac{1}{1+m}$, which is independent of $g$, and it is due to the reason provided in Dhillon and Petrakis (2002), i.e., the equilibrium input price is independent of product differentiation if the input supplier's equilibrium output and the equilibrium profit are log-linear in the input price and the market parameters.

Given the input price, $w^{c *}(m)=\frac{1}{1+m}$, the equilibrium profit of the Kth input supplier who entered the market is $\pi_{I_{k}}^{c}=\frac{n}{(1+m)^{2}(2-g+g n+2 s(1-g)(n-1))}-K$. Hence, the free entry equilibrium number of input supplier is given by $\pi_{I_{k}}^{c}=\frac{n}{(1+m)^{2}(2-g+g n+2 s(1-g)(n-1))}-K=0$ or

$$
m^{c *}=-1+\frac{n}{\sqrt{K n(2-g+g n+2 s(1-g)(n-1))}} .
$$

Assume $K<\frac{1}{8}$ so that at least one input supplier enters the market for any values of $n$ and $g$.

The equilibrium input price at the free entry equilibrium number of input suppliers is

$$
w^{c *}\left(m^{c *}\right)=\frac{\sqrt{K n(2-g+g n+2 s(1-g)(n-1))}}{n} .
$$

Proposition 1: Higher product differentiation (i.e., lower g) increases (decreases) the equilibrium input price for $s>(<) \frac{1}{2}$.

Proof: We get $\frac{\partial w^{c *}\left(m^{c *}\right)}{\partial g}=\frac{K(n-1-2 s(n-1))}{2 \sqrt{K n(2-g+g n+2 s(1-g)(n-1))}}<(>) 0$ for $s>(<) \frac{1}{2}$. 
Higher product differentiation decreases (increases) the number of input suppliers for $s>(<) \frac{1}{2} \cdot{ }^{11}$ Hence, for $s>(<) \frac{1}{2}$, the input market gets more (less) concentrated, which increases (decreases) the input price.

From (1), (2) and (6), the equilibrium profit of the $i$ th final goods producer is

$$
\pi_{i}^{c *}\left(m^{c *}\right)=\frac{(1+s(1-g)(n-1))\left(-1+\frac{\sqrt{K n(2-g+g n+2 s(1-g)(n-1))}}{n}\right)^{2}}{(2-g+g n+2 s(1-g)(n-1))^{2}} .
$$

Proposition 2: Consider Cournot competition in the final goods market. If there is free entry in the input market, the final goods producers do not prefer maximal horizontal product differentiation but prefer moderate product differentiation for $K \in\left(K^{*}, \frac{1}{8}\right)$ where $K^{*}=\frac{2 n(1-s)^{2}}{1+(n-1) s}$.

Proof: Differentiating (7) with respect to $g$ and evaluating it at $g=0$, we get

$$
\left.\frac{\partial \pi_{i}^{c *}\left(m^{c *}\right)}{\partial g}\right|_{g=0}=\frac{(n-1)[-2 n(1-s)-2 K(1+(n-1) s)+\sqrt{2}(3-2 s) \sqrt{K n(1+(n-1) s)}]}{8 n(1+(n-1) s)^{2}},
$$

which is positive for $K>\frac{2 n(1-s)^{2}}{1+(n-1) s} \equiv K^{*}$. Hence, $g=0$ is not the preferred differentiation for $K \in\left(K^{*}, \frac{1}{8}\right)$.

We also get

$$
\left.\frac{\partial \pi_{i}^{c *}\left(m^{c *}\right)}{\partial g}\right|_{g=1}=\frac{(1-n)\left(n^{2} s+(-3+4 s) \sqrt{K n(1+n)}+n(2-3 s-2 s \sqrt{K n(1+n)})\right.}{n(1+n)^{3}}<0,
$$

for $\quad K<\widehat{K}=\min \left\{\frac{n(2+(-3+n) s)^{2}}{(1+n)(1+(-1+n) s)^{2}}, \frac{n}{1+n}\right\}$, where $\frac{1}{8}<\widehat{K}$, implying $\left.\frac{\partial \pi_{i}^{c *}\left(m^{c *}\right)}{\partial g}\right|_{g=1}<0$ (i.e., $g=1$ is not the preferred differentiation) for $K \in\left[0, \frac{1}{8}\right] \cdot{ }^{12}$

Hence, if $K \in\left(K^{*}, \frac{1}{8}\right)$, neither $g=0$ nor $g=1$ is the preferred differentiation, implying firms prefer moderate differentiation in this situation.

11 We get $\frac{\partial m^{c *}}{\partial g}=-\frac{K n^{2}(n-1-2 s(n-1))}{2[K n(2-g+g n+2 s(1-g)(n-1))]^{\frac{3}{2}}}>(<) 0$ for $s>(<) \frac{1}{2}$.

12 We get $\left.\frac{\partial \pi_{i}^{c *}\left(m^{c *}\right)}{\partial g}\right|_{g=1}<0$ at $K=0,\left.\frac{\partial \pi_{i}^{c *}\left(m^{c *}\right)}{\partial g}\right|_{g=1}$ is concave with respect to $K$ and $\left.\frac{\partial \pi_{i}^{c *}\left(m^{c *}\right)}{\partial g}\right|_{g=1}=0$ at $K=\frac{n(2+(-3+n) s)^{2}}{(1+n)(1+(-1+n) s)^{2}}$ and at $K=\frac{n}{(1+n)}$, where $\frac{1}{8}<\widehat{K}=\min \left\{\frac{n(2+(-3+n) s)^{2}}{(1+n)(1+(-1+n) s)^{2}}, \frac{n}{1+n}\right\}$, implying $\left.\frac{\partial \pi_{i}^{c *}\left(m^{c *}\right)}{\partial g}\right|_{g=1}<0$, for $K<\frac{1}{8}$. 
If $s=1$, the condition in Proposition 2 always holds since $K>0$. However, if $s=0$, the condition in Proposition 2 holds provided $K>2 n$ but this is not feasible since we assume $K<\frac{1}{8}$, so that at least one input supplier enters for any values of $n$ and $g$. Hence, the condition in Proposition 2 does not hold for $s=0$. Since $\frac{\partial K^{*}}{\partial s}<0$, $K>K^{*}(s=1)$ and $K<K^{*}(s=0)$, there is a critical $s$, say, $s^{*}$, such that $K>K^{*}$ for $s>s^{*}$, implying that the final goods producers' do not prefer maximal horizontal product differentiation but prefer moderate differentiation if product differentiation does not increase the market size significantly.

The reason for the above result is as follows. If product differentiation does not increase the market size significantly, a higher product differentiation creates two opposing effects on the profits of the final goods producers. On one hand, it tends to increase the profits of the final goods producers by reducing competition, but, on the other hand, it tends to increase the input price by increasing concentration in the input sector. The rising input price may not encourage the final goods producers to do maximal differentiation.

It is worth mentioning that free entry in the input market is important for our analysis. If the number of input suppliers is given exogenously, the input price is $w^{c *}(m)=\frac{1}{1+m}$, implying that there is no input-price effect following product differentiation but product differentiation helps to increase the profits of the final goods producers by reducing competition. In this situation, the final goods producers prefer maximal differentiation. ${ }^{13}$

\subsection{Bertrand Competition in the Final Goods Market}

We show in this subsection that the qualitative results under Cournot competition remains under Bertrand competition in the final goods market. We consider a game like subsection 2.1 with the exception that the final goods producers compete like Bertrand oligopolists.

Since the analysis and the proof are like Section 3.1, to save space, we mention the result in the text and relegate the calculations to Appendix A.

Proposition 3: Consider Bertrand competition in the final goods market. If there is free entry in the input market, the final goods producers do not prefer maximal

13 If the number of input suppliers is given exogenously, the profit of the $i$ th final goods producer is $\pi_{i}^{c *}=\frac{m^{2}(1+s(1-g)(n-1))}{(1+m)^{2}(2-g+g n+2 s(1-g)(n-1))^{2}}$, and $\frac{\partial \pi_{i}^{c *}}{\partial g}=\frac{m^{2}(n-1)(-2+s(4-g-2 n+g n+2(1-g)(n-1) s))}{(1+m)^{2}(2-g+g n+2 s(1-g)(n-1))^{3}}<0$. 
horizontal product differentiation but prefer moderate differentiation for $K \in\left(K^{*}, \frac{1}{8}\right)$ where $K^{*}=\frac{2 n(1-s)^{2}}{1+(n-1) s}$.

The reason for the above result is like the reason discussed after Proposition 2.

\section{Monopoly Input Supplier with Increasing Returns to Scale Technology}

\subsection{Cournot Competition in the Final Goods Market}

Now we consider a model like the previous section with the exception that there is a monopolist input supplier with increasing returns to scale technology. We consider a monopolist input supplier to show the effects of scale economies only by assuming away competition in the input market. There are two reasons for looking at economies of scale in input production. First, as mentioned in Besanko et al. (2013), the input productions often experience economies of scale. Second, we show that endogenous input market structure is not necessary for the results derived in the previous section. Our qualitative results remain as long as the input-price effect discussed in the previous section occurs following a higher product differentiation, and economies of scale in input production is another candidate to create that type of input-price effect.

Assume that the total cost of production faced by the input supplier is $T C=c I-d I^{2}$, with $c<1, c-2 d I>0$, where $c, d>0$ and $I$ is the total input produced. This is a simplified version of the textbook cost function $T C=a+c I-d I^{2}+e I^{3}$. To show the implications of increasing returns in input production in the simplest way, we assume that $a=e=0$. The properties of the cost function considered here are as follows. We get the average cost as $A C=c-d I$ and the marginal cost as $M C=c-2 d I<A C$. Given our assumption of $c-2 d I>0$, both the marginal and average costs are positive.

The equilibrium output of the $i$ th final goods producer is given by (2). Hence, the input demand curve is $w^{c i}=\frac{n-(2-g) I-g n I-2 S I(1-g)(n-1)}{n}$. The monopolist input supplier determines its output by maximising the following expression:

$$
\operatorname{Max}_{I}\left(\frac{n-(2-g) I-g n I-2 s I(1-g)(n-1)}{n}\right) I-\left(c I-d I^{2}\right) .
$$

The equilibrium input production is

$$
I^{c i *}=\frac{(1-c) n}{2(2-g+g n-d n+2 s(1-g)(n-1))} .
$$


We get $c-2 d I^{c i *}>0$ for $d<\frac{c(2-g+g n+2 s(1-g)(n-1))}{n} \equiv \overline{d^{c i}}$, which is assumed to hold.

The equilibrium input price is

$$
w^{c i *}=\frac{1}{2}\left(1+c-\frac{(1-c) d n}{2-g+g n-d n+2 s(1-g)(n-1)}\right) .
$$

Proposition 4: Higher product differentiation (i.e., lower g) increases (decreases) the equilibrium input price for $s>(<) \frac{1}{2}$.

Proof: We get $\frac{\partial w^{c i *}}{\partial g}=\frac{d n(1-c)(n-1)(1-2 s)}{2(2-g+g n-d n+2 s(1-g)(n-1))^{2}}<(>) 0$ for $s>(<) \frac{1}{2}$.

If $s>(<) \frac{1}{2}$, a higher product differentiation decreases (increases) input supply ${ }^{14}$ and increases (decreases) the equilibrium input price due to increasing returns in input production. Proposition 4 is like Proposition 1 and it plays the important role in determining the final goods producers' preference for product differentiation.

The equilibrium profit of the $i$ th final goods producer is

$$
\pi_{i}^{c i *}=\frac{(1-c)^{2}(1-s(1-g-n+g n))}{4(2-g+g n-d n+2 s(1-g)(n-1))^{2}} .
$$

Proposition 5: Consider Cournot competition in the final goods market. If there is a monopolist input supplier with increasing returns to scale technology, the final goods producers do not prefer maximal differentiation but prefer moderate differentiation for $d^{*}<d<\min \left\{\bar{d}, \overline{d^{c i}}\right\}$, where $d^{*}=\frac{2(1-s)(1+(n-1) s)}{n s}, \bar{d}=\frac{2+s(n-3)}{n s}$ and $\overline{d^{c i}}=\frac{c(2-g+g n+2 s(1-g)(n-1))}{n}$.

Proof: Differentiating (11) with respect to $g$ and evaluating it at $g=0$, we get $\left.\frac{\partial \pi_{i}^{c i *}}{\partial g}\right|_{g=0}=\frac{(1-c)^{2}(n-1)(-2+s(4-2 s+n(-2+d+2 s)))}{4(2-d n+2 s(n-1))^{3}}$, which is positive for $d>\frac{2(1-s)(1+(n-1) s)}{n s} \equiv d^{*}$. Hence, $g=0$ is not the preferred differentiation for $d>d^{*}$.

We also get

$$
\left.\frac{\partial \pi_{i}^{c i *}}{\partial g}\right|_{g=1}=-\frac{(1-c)^{2}(n-1)(-2+s(3+(d-1) n))}{4(-1+n(d-1))^{3}}<0
$$

for $d<\frac{2+s(n-3)}{n s} \equiv \bar{d}$, where $\bar{d}>(<) \overline{d^{c i}}$, implying $g=1$ is not the preferred differentiation for $d<\min \left\{\bar{d}, \overline{d^{c i}}\right\}$.

14 We get that $\frac{\partial I^{c i}}{\partial g}=-\frac{(1-c) n(n-1)(1-2 s)}{2(2-g+g n-d n+2 s(1-g)(n-1))^{2}}>(<) 0$ for $s>(<) \frac{1}{2}$. 
Since $d^{*}>(<) \overline{d^{c i}}$ and $d^{*}>(<) \bar{d}$, neither $g=0$ nor $g=1$ is the preferred differentiation for $d^{*}<d<\min \left\{\bar{d}, \overline{d^{c i}}\right\}$, implying firms prefer moderate differentiation in this situation.

If $s=1$, the condition in Proposition 5 holds for $d>1$. However, if $s=0$, the condition in Proposition 5 does not hold. Since $\frac{\partial d^{*}}{\partial s}<0, d>d^{*}(s=1)$ for $d>1$ and $d<d^{*}(s=0)$, if $d>1$, we get that there is a critical $s$, say, $s^{* *}$, such that $d>d^{*}$ for $s>s^{* *}$, implying that if the economies of scale in input production is sufficiently strong, the final goods producers' do not prefer maximal horizontal product differentiation but prefer moderate differentiation if product differentiation does not increase the market size significantly.

If the scale economies in input production is sufficiently strong, a higher product differentiation creates significant adverse input-price effect when product differentiation does not increase the market size significantly. In this situation, the adverse input-price effect dominates the favourable competition reducing effect of a higher product differentiation and the firms' do not prefer maximal differentiation.

\subsection{Bertrand Competition in the Final Goods Market}

Now we show that a qualitative result like Proposition 5 remains under Bertrand competition in the final goods market. We consider a game similar to subsection 3.1 with the exception that the final goods producers compete like Bertrand oligopolists.

Since the analysis and the proof are like Section 3.1, to save space, we mention the result in the text and relegate the calculations to Appendix B.

Proposition 6: Consider Bertrand competition in the final goods market. If there is a monopolist input supplier with increasing returns to scale technology, the final goods producers do not prefer maximal horizontal product differentiation but prefer moderate differentiation for $d \in\left(d^{*}, \overline{d^{b i}}\right)$ where $d^{*}=\frac{2(1-s)(1+(n-1) s)}{n s}$ and $\overline{d^{b i}}=\frac{c(2-3 g+g n+2 s(1-g)(n-1))(1+g(n-1)(1-s)+s(n-1))}{n(1-2 g+g n+(1-g)(n-1) s)}$.

\section{Conclusion}

We provide a new rationale for not creating maximal horizontal product differentiation. We show that the final goods producers may not prefer maximal differentiation but may prefer moderate differentiation under both Cournot and Bertrand competition in the final goods market if product differentiation does not 
increase the market size significantly and there is either free entry in the input market or the input supplier has increasing returns to scale technology. Hence, our reasons for moderate horizontal product differentiation, which are based on the input market structure, input production technology and the market expansion effect, are different from the existing reasons of mixed pricing strategy, endogenous leadership, no-buy option for the consumers and the relative performance incentive schemes.

Acknowledgments: We would like to thank two anonymous referees of this journal, Noriaki Matsushima and Horst Zank for valuable comments and suggestions. The usual disclaimer applies.

\section{Appendix}

\section{A: Bertrand Competition Under Free Entry in the Input Sector}

For the inverse market demand function $P_{i}=1-\alpha q_{i}-g \sum_{j=1}^{n} q_{j}$, where $\alpha=1+$ $i \neq j$

$s(n-1)(1-g)$, the corresponding demand function is $q_{i}=\frac{\alpha-g-p_{i}(\alpha+g(n-2))+g \sum_{i \neq j} p_{j}}{(\alpha-g)(\alpha+g(n-1))}$.

Given the input price $w$, the $i$ th final goods producer maximises $\left(p_{i}-w\right) q_{i}$ with respect to price. The equilibrium price and output can be found as $p_{i}^{b *}=$ $\frac{-(1+(n-1) s)(1+w)+g(1+2 w-n w+(n-1)(1+w) s)}{(-2+3 g-g n-2(1-g)(n-1) s)}$ and $q_{i}^{b *}=\frac{(1-2 g+g n+(1-g)(n-1) s)(1-w)}{(2-3 g+g n+2(1-g)(n-1) s)(1+g(n-1)(1-s)-s+n s)}, i=1$, $2, \ldots, n$, respectively.

The total input demand is $n q_{i}^{b *}=I=\frac{n(1-2 g+g n+(1-g)(n-1) s)(1-w)}{(2-3 g+g n+2(1-g)(n-1) s)(1+g(n-1)(1-s)-s+n s)}$, which gives $w^{b}=\frac{n-(2-g) I-g n I-2 s I(1-g)(n-1)+\frac{g^{2}(n-1) I}{(1-2 g+g n+(1-g)(n-1) s)}}{n}$.

If $m$ input suppliers entered the market, the $k$ th input supplier determines its

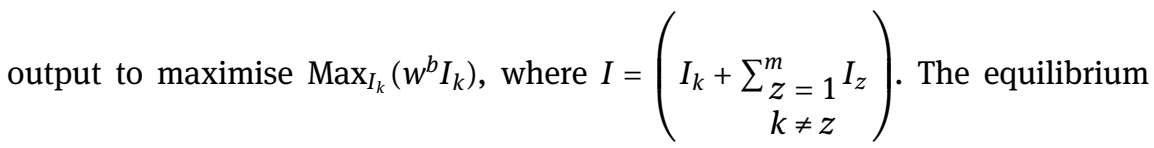
input production is $I_{k}^{b *}=\frac{n(1+(n-1) s+g(-2+n+s-n s))}{(1+m)(-2+3 g-g n-2 s(1-g)(n-1))(-1-g(n-1)(1-s)+s-n s)}$. Hence, for a given number of input suppliers, $m$, the equilibrium input price is $w^{b *}(m)=\frac{1}{1+m}$, which is independent of $g$. This is similar to the result under Cournot competition in 
the final goods market and as mentioned in section 2.1, it is due to the reason provided in Dhillon and Petrakis (2002).

Given the input price, $w^{b *}(m)=\frac{1}{1+m}$, the equilibrium profit of the $k$ th input supplier who entered the market is $\pi_{I_{k}}^{b}=\frac{n(1+(n-1) s+g(-2+n+s-n s))}{(1+m)^{2}(-2+3 g-g n-2 s(1-g)(n-1))(-1-g(n-1)(1-s)+s-n s)}-K$. Hence, the free entry equilibrium number of input suppliers is given by $\pi_{I_{k}}^{b}=$ $\frac{n(1+(n-1) s+g(-2+n+s-n s))}{(1+m)^{2}(-2+3 g-g n-2 s(1-g)(n-1))(-1-g(n-1)(1-s)+s-n s)}-K=0$ or

$$
m^{b *}=-1 \quad+\frac{n(1+(n-1) s+g(-2+n+s-n s))}{\sqrt{\begin{array}{l}
K n(1-2 g+g n+(1-g)(n-1) s)(-2+3 g-g n-2 s(1-g)(n-1)) \\
(-1-g(n-1)(1-s)+s-n s)
\end{array}}} .
$$

Assume $K<\frac{1}{8}$ so that at least one input supplier enters the market for any values of $n$ and $g$.

The equilibrium profit of the $i$ th final goods producer is $\pi_{i}^{b *}\left(m^{b *}\right)=$

$$
\left(\frac{K(1-g)(1+(n-1) s)}{n(2-3 g+g n+2 s(1-g)(n-1))^{2}}\right)\left(-1+\frac{n(1+(n-1) s+g(-2+n+s-n s))}{\sqrt{\begin{array}{l}
K n(1-2 g+g n+(1-g)(n-1) s) \\
(-2+3 g-g n-2(1-g)(n-1) s) \\
(-1-g(n-1)(1-s)+s-n s)
\end{array}}}\right)^{2} .
$$

Differentiating $\pi_{i}^{b *}\left(m^{b *}\right)$ with respect to $g$ and evaluating it at $g=0$, we get

$$
\begin{aligned}
& \left.\frac{\partial \pi_{i}^{b *}\left(m^{b *}\right)}{\partial g}\right|_{g=0}=\left(\frac{n-1}{8 n^{2}(1+(n-1) s)^{4}}\right)\left(n \sqrt{2}(1+(n-1) s)-2 \sqrt{K n(1+(n-1) s)^{3}}\right) \\
& \left(-n(1-s) \sqrt{2}(1+(n-1) s)+\sqrt{K n(1+(n-1) s)^{3}}\right)
\end{aligned}
$$

which is positive for $K>\frac{2 n(1-s)^{2}}{1+(n-1) s} \equiv K^{*}$. Hence, $g=0$ is not the preferred differentiation for $K \in\left(K^{*}, \frac{1}{8}\right)$. Since we are looking at the change in profit with respect to $g$ and evaluating it at $g=0$, it is intuitive that the critical conditions are the same under Cournot and Bertrand competition since the type of competition does not matter at $g=0$.

We also get $\left.\frac{\partial \pi_{i}^{b *}\left(m^{b *}\right)}{\partial g}\right|_{g=1}=-\frac{\left[n-n^{2}+n(n-1) \sqrt{K}\right]^{2}(1+(n-1) s)}{n^{3}(n-1)^{3}}<0$, implying that $g=1$ is not the preferred differentiation.

Hence, if $K \in\left(K^{*}, \frac{1}{8}\right)$, neither $g=0$ nor $g=1$ is the preferred differentiation, implying firms prefer moderate differentiation in this situation. 


\section{B: Bertrand Competition Under Monopolist Input Supplier with Economies of Scale}

Given the demand function, the $i$ th final goods producer maximises $\left(p_{i}-w\right) q_{i}$ with respect to price. The equilibrium price and output can be found as $p_{i}^{b i *}=$ $\frac{-(1+(n-1) s)(1+w)+g(1+2 w-n w+(n-1)(1+w) s)}{(-2+3 g-g n-2(1-g)(n-1) s)}$ and $q_{i}^{b i *}=\frac{(1-2 g+g n+(1-g)(n-1) s)(1-w)}{(2-3 g+g n+2(1-g)(n-1) s)(1+g(n-1)(1-s)-s+n s)}, i=1$, $2, \ldots, n$, respectively. gives

The total input demand is $n q_{i}^{b i *}=I=\frac{n(1-2 g+g n+(1-g)(n-1) s)(1-w)}{(2-3 g+g n+2(1-g)(n-1) s)(1+g(n-1)(1-s)-s+n s)}$, which

$$
w^{b i}=\frac{n-(2-g) I-g n I-2 s I(1-g)(n-1)+\frac{g^{2}(n-1) I}{(1-2 g+g n+(1-g)(n-1) s)}}{n} .
$$

The monopolist input supplier determines its output by maximising $\operatorname{Max}_{I}\left[w^{b i} I-\left(c I-d I^{2}\right)\right]$. The equilibrium input production is

$$
I^{b i *}=\frac{(1-c)}{2\left(\frac{2+2(n-1) s+g(n-1)(1-2 s)-\frac{g^{2}(n-1)}{1-2 g+g n+(1-g)(n-1) s}}{n}-d\right)} .
$$

We get $c-2 d I^{b i *}>0$ for $d<\frac{c(2-3 g+g n+2 s(1-g)(n-1))(1+g(n-1)(1-s)+s(n-1))}{n(1-2 g+g n+(1-g)(n-1) s)} \equiv \overline{d^{b i}}$, which is assumed to hold.

Inserting (B2) into (B1) for I gives the equilibrium input price, $w^{b i *}$. Using $p_{i}^{b i *}$, $q_{i}^{b i *}$ and $w^{b i *}$, we get the equilibrium profit of the $i$ th final goods producer as

$$
\begin{aligned}
&(1-c)^{2}(1-g)(1+(n-1) s)(1-2 g+g n+(1-g)(n-1) s) \\
& \pi_{i}^{b i *}=(1+g(n-1)(1-s)-s+n s) \\
& 4\left(2-5 g+3 g^{2}-d n+3 g n+2 d g n-4 g^{2} n-d g n^{2}+g^{2} n^{2}\right. \\
&\left.+(1-g)(n-1)(4-d n-g(5-3 n)) s+2(1-g)^{2}(n-1)^{2} s^{2}\right)^{2}
\end{aligned} .
$$

Differentiating $\pi_{i}^{b i *}$ with respect to $g$ and evaluating it at $g=0$, we get $\left.\frac{\partial \pi_{i}^{b i *}}{\partial g}\right|_{g=0}=\frac{(1-c)^{2}(n-1)(2-s(4-2 s-n(2-d-2 s)))}{4(2-d n+2(n-1) s)^{3}}\left(-n(1-s) \sqrt{2}(1+(n-1) s)+\sqrt{K n(1+(n-1) s)^{3}}\right)$, which is positive for $d>\frac{2(1-s)(1+(n-1) s)}{n s} \equiv d^{*}$ where $d^{*}>(<) \overline{d^{b i}}$. Hence, $g=0$ is not the preferred differentiation for $d \in\left(d^{*}, \overline{d^{b i}}\right)$. Since we are looking at the change in profit with respect to $g$ and evaluating it at $g=0$, it is intuitive that the critical 
conditions are the same under Cournot and Bertrand competition since the type of competition does not matter at $g=0$.

We also get $\left.\frac{\partial \pi_{i}^{b i *}}{\partial g}\right|_{g=1}=-\frac{(1-c)^{2}(1+s(n-1))}{4 n(n-1)(d-1)^{2}}<0$, implying that $g=1$ is not the preferred differentiation. Since the final goods producers get zero profits under Bertrand competition if the products are homogeneous, they always prefer some differentiation in this situation.

Hence, if $d \in\left(d^{*}, \overline{d^{b i}}\right)$, neither $g=0$ nor $g=1$ is the preferred differentiation, implying firms prefer moderate differentiation in this situation.

\section{References}

Aghion, P., N. Bloom, R. Blundell, R. Griffith, and P. Howitt. 2005. “Competition and Innovation: An Inverted U-Relationship." Quarterly Journal of Economics 120: 701-28.

Ardelean, A. 2006. How Strong is the Love of Variety. Mimeo: Purdue University.

Besanko, D., D. Dranove, M. Shanley, and S. Schaefer. 2013. Economics of Strategy, 6th ed. Singapore: John Wiley \& Sons.

Bowley, A. L. 1924. The Mathematical Groundwork of Economics: An Introductory Treatise. Oxford: Oxford University Press.

Brekke, K. R., and O. R. Straume. 2004. "Bilateral Monopolies and Location Choice." Regional Science and Urban Economics 34: 275-88.

Choné, P., and L. Linnemer. 2020. "Linear Demand Systems for Differentiated Goods: Overview and User's Guide." International Journal of Industrial Organization 73: 102663.

Cintio, M. D. 2006. On the Hotelling Principle of Minimum Differentiation: Imitation and Crowd. Italy: Mimeo, University of Lecce.

D’Aspremont, C., J. Jaskold Gabszewicz, and J. F. Thisse. 1979. “On Hotelling's Stability in Competition." Econometrica 47: 1145-50.

Dhillon, A., and E. Petrakis. 2002. "A Generalised Wage Rigidity Result.” International Journal of Industrial Organization 20: 285-311.

Eaton, B. C., and R. G. Lipsey. 1975. "The Principle of Minimum Differentiation Reconsidered Some New Developments in the Theory of Spatial Competition." Review of Economic Studies 29: 27-49.

Economides, N. 1984. “The Principle of Minimum Differentiation Revisited.” European Economic Review 24: 345-68.

Economides, N. 1986. "Minimal and Maximal Product Differentiation in Hotelling’s Duopoly.” Economics Letters 21: 67-71.

Fanti, L., and N. Meccheri. 2014. "Profits and Competition under Alternative Technologies in a Unionized Duopoly with Product Differentiation." Research in Economics 68: 157-68.

Fee, C. E., and S. Thomas. 2004. "Sources of Gains in Horizontal Mergers: Evidence from Customer, Supplier, and Rival Firms." Journal of Financial Economics 74: 423-60.

Friedman, J. W., and J.-F. Thisse. 1993. "Partial Collusion Fosters Minimum Product Differentiation." Rand Journal of Economics 24: 631-45.

Friedson, A. I., and J. Li. 2015. "The Impact of Agglomeration Economies on Hospital Input Prices." Health Economics Review 5, Article 38. https://doi.org/10.1186/s13561-015-0075-1. 
Guo, L. 2006. “Consumption Flexibility, Product Configuration, and Market Competition.” Marketing Science 25: 116-30.

Haskel, J., A. Iozzi, and T. Valletti. 2013. "Market Structure, Countervailing Power and Price Discrimination: The Case of Airports." Journal of Urban Economics 74: 12-26.

Hefti, A. 2018. "Limited Attention, Competition and Welfare." Journal of Economic Theory 178: 318-59.

Holmes, T. J. 1999. "Localization of Industry and Vertical Disintegration." Review of Economics and Statistics 81: 314-25.

Hotelling, H. 1929. "Stability in Competition." Economic Journal 39: 41-57.

Inomata, K. 2018. Profitable Competition, Mimeo, Competition Policy Research Center (CPRC), Japan Fair Trade Commission.

Iyengar, S. S., and E. Kamenica. 2010. "Choice Proliferation, Simplicity Seeking, and Asset Allocation." Journal of Public Economics 94: 530-9.

Jehiel, P. 1992. "Product Differentiation and Price Collusion." International Journal of Industrial Organization 10: 633-41.

Karlson, S. H. 1985. "Spatial Competition with Location-dependent Costs." Journal of Regional Science 25: 201-14.

Kawasaki, A., and A. Matsushima. 2019. Competition between International Connecting Flights and the Role of Airport Landing Fees. Japan: Mimeo, Institute of Social and Economic Research, Osaka University.

Kim, H., and K. Serfes. 2006. "A Location Model with Preference for Variety." Journal of Industrial Economics 54: 569-95.

Kou, Z., and M. Zhou. 2015. “Hotelling's Competition with Relative Performance Evaluation.” Economics Letters 130: 69-71.

Li, J. 2013. "Intermediate Input Sharing in the Hospital Service Industry." Regional Science and Urban Economics 43: 888-902.

Liang, W. J., H. Hwang, and C. C. Mai. 2006. "Spatial Discrimination: Bertrand vs. Cournot with Asymmetric Demands.” Regional Science and Urban Economics 36: 790-802.

Malone, T., and J. L. Lusk. 2017. "The Excessive Choice Effect Meets the Market: A Field Experiment on Craft Beer Choice.” Journal of Behavioral and Experimental Economics 67: 8-13.

Matsushima, N. 2004. "Technology of Upstream Firms and Equilibrium Product Differentiation." International Journal of Industrial Organization 22: 1091-114.

Matsushima, N. 2006. “Industry Profits and Free Entry in Input Markets.” Economics Letters 93: 329-36.

Matsushima, N. 2009. "Vertical Mergers and Product Differentiation." Journal of Industrial Economics 57: 812-34.

Matsumura, T., and N. Matsushima. 2010. "When Small Firms Fight Back against Large Firms in R\&D Activities" B.E. Journal of Economic Analysis \& Policy 10. Article 81. https://doi.org/10. 2202/1935-1682.2597.

Matsumura, T., and N. Matsushima. 2011. "Collusion, Agglomeration, and Heterogeneity of Firms." Games and Economic Behavior 72: 306-13.

Matsumura, T., and N. Matsushima. 2012. "Locating outside a Linear City May Benefit Consumers." Journal of Regional Science 52: 420-32.

Meza, S., and M. Tombak. 2009. "Endogenous Location Leadership." International Journal of Industrial Organization 27: 687-707.

Mukherjee, A. 2019. "Profit Raising Entry in a Vertical Structure." Economics Letters 183: 108543-4. 
Mukherjee, A., U. Broll, and S. Mukherjee. 2008. “Unionized Labor Market and Licensing by a Monopolist.” Journal of Economics 93: 59-79.

Mukherjee, A., U. Broll, and S. Mukherjee. 2009. "The Welfare Effects of Entry: the Role of the Input Market.” Journal of Economics 98: 189-201.

Naylor, R. 2002. “Industry Profits and Competition under Bilateral Oligopoly." Economics Letters 77: $169-75$.

Osborne, M. J., and C. Pitchik. 1987. "Equilibrium in Hotelling's Model of Spatial Competition.” Econometrica 55: 911-22.

Pal, D. 1998. “Does Cournot Competition Yield Spatial Agglomeration?" Economics Letters 60: 49-53.

Pazgal, A., D. Soberman, and R. Thomadsen. 2016. "Maximal or Minimal Differentiation in a Hotelling Market? A Fresh Perspective." Customer Needs and Solutions 3: 42-7.

Raith, M. 2003. “Competition, Risk, and Managerial Incentives." American Economic Review 93: 1425-36.

Sacco, D., and A. Schmutzler. 2011. "Is There a U-Shaped Relation Between Competition and Investment?" International Journal of Industrial Organization 29: 65-73.

Salop, S. C. 1979. “Monopolistic Competition with Outside Goods.” The Bell Journal of Economics 10: $141-56$.

Shimizu, D. 2002. "Product Differentiation in Spatial Cournot Markets." Economics Letters 76: 317-22.

Singh, N., and X. Vives. 1984. "Price and Quantity Competition in a Differentiated Duopoly." Rand Journal of Economics 15: 546-54.

Shubik, M., and R. Levitan. 1980. Market Structure and Behaviour. Cambridge, MA: Harvard University Press.

Sun, C.-H. 2014. "Cournot and Bertrand Competition in a Model of Spatial Price Discrimination with Differentiated Products." The B.E. Journal of Theoretical Economics 14: 251-72.

Tabuchi, T., and J.-F. Thisse. 1995. "Asymmetric Equilibria in Spatial Competition.” International Journal of Industrial Organization 13: 213-27.

Tyagi, R. K. 1999. “On the Effects of Downstream Entry.” Management Science 45: 59-73.

Vickrey, W. S. 1964. Microstatics. New York and Burlingame: Harcourt, Brace \& World.

Wang, L. F. S., and J.-Y. Lee. 2015. "Profit-Raising Entry in Vertically Related Markets.” Managerial and Decision Economics 36: 401-7. 